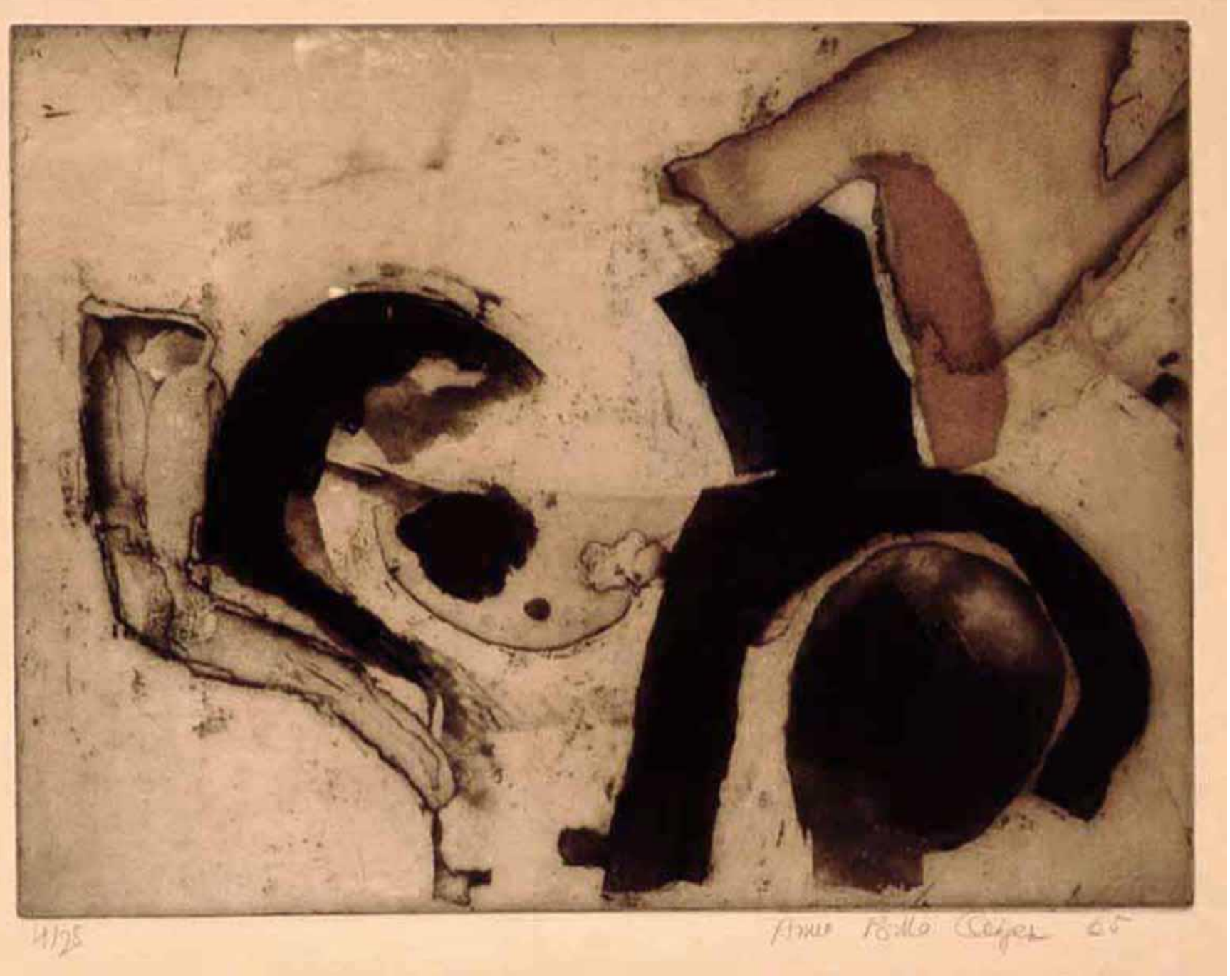

Pintoras e gravadoras expressivas: um capítulo à parte. Informalismo e Expressionismo-abstrato no Brasil

Expressive women painters and printmakers: a unique chapter. Informalism and Abstract Expressionism in Brazil

\title{
Ana Avelar
}

Como citar:

AVELAR, A. Pintoras e gravadoras expressivas: Um capítulo à parte. Informalismo e Expressionismo-abstrato no Brasil. MODOS: Revista de História da Arte, Campinas, SP, v. 5, n. 1, p. 160-177, 2021. DOI: 10.20396/modos.v5i1.8664221. Disponível em: $<$ https://periodicos.sbu.unicamp.br/ojs/index.php/mod/article/view/86 $64221>$.

Imagem: Anna Bella Geiger - A um Azul Profundo, llimitado...,1965, água-tinta e relevo em cores sobre papel, $59,8 \mathrm{~cm} \times 49,4 \mathrm{~cm}$, acervo MAC USP. 


\title{
Pintoras e gravadoras expressivas: um capítulo à parte. Informalismo e Expressionismo-abstrato no Brasil
}

\author{
Expressive women painters and printmakers: a unique chapter. Informalism \\ and Abstract Expressionism in Brazil
}

\begin{abstract}
Ana Avelar*

\section{Resumo}

Neste artigo, visa-se estabelecer considerações sobre a arte informalista e expressionista abstrata no Brasil, a partir da atuação de gravadoras e pintoras que aderiram às abstrações não-geométricas ou experimentaram nessa direção, entre as décadas de 1950 e 1960, sendo que muitas também desempenharam funções pedagógicas. Nomes como Fayga Ostrower e Yolanda Mohalyi são mais conhecidos, tendo sido objeto de textos críticos de época e de exposições individuais ao longo dos anos. $\mathrm{Na}$ gravura, chamam atenção Anna Bella Geiger e Edith Behring, além do ateliê de gravura do Museu de Arte Moderna do Rio de Janeiro - MAM RJ, na qual atuaram como estudante e professora, respectivamente. Entretanto, a pintora Sheila Brannigan é uma referência pouco lembrada, embora frequente na imprensa da época. Conceitualmente esta reflexão apoiar-se-á, por um lado, na crítica brasileira de meados do século XX sobre essas artistas; por outro, nos estudos de orientação feminista sobre o Expressionismo Abstrato, trazendo novas análises sobre a produção de artistas como Elaine de Kooning, Hedda Sterne e Helen Frankenthaler. O corpus eleito para a pesquisa concentra-se na coleção do Museu de Arte Contemporânea da Universidade de São Paulo - MAC USP, uma vez que conta com exemplares significativos da obra das artistas mencionadas.
\end{abstract}

Palavras-chave

Expressionismo Abstrato. Informalismo. Artistas mulheres. Abordagem feminista.

\begin{abstract}
This article discusses Informalist and Abstract Expressionist art in Brazil, focused on the production of printmakers and painters who adhered to non-geometric abstractions or experimented in this direction, between 1950s and 1960s, many of whom also developed pedagogical activities in studios and museums. Names like Fayga Ostrower and Yolanda Mohalyi are better known, having been the subject of art criticism at the time and having solo shows over the years. In the field of printmaking, attention is drawn to Anna Bella Geiger and Edith Behring, student and teacher, respectively, at the important printmaking studio at the Museum of Modern Art in Rio de Janeiro - MAM RJ. However, the painter Sheila Brannigan is rarely remembered, although much discussed by the press of the time. Conceptually, on the one hand, I will discuss Brazilian criticism about these artists; on the other, in feminist-oriented studies particularly about Abstract Expressionism, I bring in new views about artists such as Elaine de Kooning, Hedda Sterne and Helen Frankenthaler. The corpus chosen for this research is based on the collection of the Museum of Contemporary Art of the University of São Paulo - MAC USP, which holds exemplary works of these artists.
\end{abstract}

\section{Keywords}

Abstract Expressionism. Informalism. Women artists. Feminist art theory. 
Mário Pedrosa, ao comentar a gravura informalista de Anna Bella Geiger, o faz de modo introdutório, visando elogiar o engajamento técnico da artista. O crítico se refere a uma "gratuidade tachista", interessando a ele o trabalho consecutivo da artista, visto como uma investigação do corpo, nos anos 19601. Para compreender o que constituiria essa "gratuidade tachista", é preciso recuar no tempo, trazendo textos que o crítico escrevera anos antes sobre Fayga Ostrower, um nome do Informalismo estabelecido entre nós e, aliás, - e talvez não coincidentemente - professora de Geiger.

Recentemente, a própria Geiger rememorou a história de seu percurso artístico trazendo apontamentos sobre sua obra abstrato-expressiva2:

meu trabalho de 1953 à 1965 se desenvolveu dentro do rigor do abstracionismo informal, sim. (...) minhas obras de teor abstrato vinham participando, de modo atuante, desde 1953 até 1964: mostras nacionais e internacionais (como por exemplo na I Exposição de Arte Abstrata Brasileira) e outro exemplo o primeiro prêmio na Mostra Internacional de Grabado em Havana. (...) A minha iniciação na arte foi feita no ateliê de Fayga Ostrower e com Anna Levy Deinhardt, uma historiadora da arte de Berlim. Sempre foi enfatizada a posição ou a função do artista dentro do fazer arte (Geiger apud Rubino, 2016: 103)

Pedrosa escreve sobre Fayga Ostrower em 1957, por ocasião de sua premiação na $4^{a}$ Bienal de São Paulo. Nessa ocasião, o crítico argumenta elogiosamente que na obra da gravadora "os efeitos poéticos não são apenas efeitos do acaso", pois "em nome da fantasia, ela controla o acaso, o manipula", considerando-a um paradoxo por operar pela gravura na linguagem "tachista". Embora 0 artigo esteja repleto de elogios à singularidade da poética abstrato-informal de Fayga, Pedrosa finaliza taxativo: "Fayga é forte, caminha por si só, sabe o que faz. Mas o seu exemplo não é para ser seguido" (1992: 102). Em outras palavras, Pedrosa parece dizer que, embora a obra de Fayga e mesmo seu processo de "filtragem" de elementos plásticos sejam extraordinários, não é indicado que outros partilhem as escolhas da artista.

A colocação soa estranhamente judicativa, constituindo talvez um mau momento desse crítico brilhante, cuja contribuição, proveniente de um olhar sagaz e uma dedicação absoluta para a sistematização do cenário artístico no país durante cerca de quatro décadas, nunca poderá ser negada 4 . Por outro lado, Iberê Camargo, ícone da pintura abstrato-expressiva, era, para o crítico, "no nosso panorama, uma individualidade solitária e cativante". Mesmo quando fazia "pintura da moda" apresentava "sua maneira insólita, egocêntrica e para a qual o único ingrediente consciente que entra é uma deliberada vontade, mas sem medida, de inortodoxia" (Pedrosa apud Salvatori, 2012:15).

Em outras palavras, a independência de Fayga era problemática, enquanto que a "inortodoxia" de lberê caracterizava-o positivamente. Nesse sentido, não parece ser apenas o fator informalista a questão que Pedrosa critica também na produção de lberê -, mas a singularidade da atitude, que em Fayga é inadequada, enquanto que em Iberê parece ser uma necessária insubordinação.

Diante disso, perguntamo-nos se teria esse julgamento dito respeito apenas à obra de Fayga ou também serviriam para outros e outras artistas, que ousaram escolher essa trilha? Representaria essa a posição de uma parcela da crítica ou do ambiente artístico como um todo?

Neste artigo, proponho estabelecer considerações sobre a produção informalista e expressionista abstrata no Brasil, a partir da atuação de gravadoras e pintoras que aderiram às abstrações não- 
geométricas ou experimentaram nessa direção, entre as décadas de 1950 e 1960, tendo muitas se constituído como mestras, formando alunos e alunas. Dentro desse cenário, a presença de mulheres é marcante em termos de aprofundamento da pesquisa artística. Nomes como Fayga Ostrower e Yolanda Mohalyi são mais conhecidos, tendo sido objeto de textos críticos de época que chegaram até nós e de individuais em museus e galerias ao longo dos anos. Na gravura, há os trabalhos de Anna Bella Geiger e Edith Behring, para não esquecermos do ateliê de gravura do Museu de Arte Moderna do Rio de Janeiro - MAM RJ, no qual atuaram como estudante e professora, respectivamente. Entretanto, a pintora Sheila Brannigan é uma referência pouco lembrada, embora frequente na imprensa da época. Além disso, há ainda pintoras que experimentaram com essas linguagens, tendo mesmo escolhido encaminhamentos abstrato-geométricos, como Maria Leontina e Judith Lauand. Para amparar esta discussão, irei valer-me da coleção do Museu de Arte Contemporânea da Universidade de São Paulo - MAC USP, uma vez que ela conta com exemplares significativos da obra das artistas mencionadas. Conceitualmente a reflexão apoiar-se-á, por um lado, na crítica brasileira, sobressaindo a voz antagonista de Mário Pedrosa; por outro, nos estudos de orientação feminista sobre o Expressionismo Abstrato, que trazem novas análises sobre a produção de artistas como Elaine de Kooning, Hedda Sterne e Helen Frankenthaler.

\section{Fayga é forte, mas seu exemplo não deve ser seguido}

Seria leviano supor que um crítico consciencioso como Pedrosa não estivesse atento ao caráter ambíguo de sua frase. Devido a inúmeros estudos que buscaram explicar a defesa da arte concreta e da neoconcreta por parte do crítico, sabe-se muito sobre sua afirmação sistemática de uma visão para a arte brasileira via construtivismo como projeto político para a arte nacional. Menos, no entanto, se conhece sobre seu interesse pelas poéticas gestuais, sendo que o estudo sobre a caligrafia sinojaponesa e sua influência para a pintura abstrata de meados do século $X X$ já foi publicado e discutido, bem como seu desapreço pelo grupo Gutai e o Informalismo japonês ${ }^{5}$. Ao ser entrevistado por Geiger e Fernando Cocchiarale sobre sua visão acerca das abstrações não-geométricas, Pedrosa declarou:

O Brasil é um país de construção nova e eu achava que a arte concreta foi que deu essa disciplina no nível da forma. Já o Informalismo era uma arte pessimista, muito pessimista e refletiu o que se passava no mundo. Uma arte de posição filosófica toda subjetiva, introjetiva. Era uma posição que não implicava uma mensagem, uma atitude de quem vê mais longe. Era um grito do artista, uma interjeição permanente. Eu acho que era simpática, mas uma arte moderna como essa não carregava uma mensagem mundial. Mundial sim, mas perdidamente, sem uma diretriz (Pedrosa apud Cocchiarale e Geiger, 1987: p.105).

O depoimento de Pedrosa evidencia sua declarada defesa de um movimento artístico em termos projetivos em detrimento de outro, que via como "pessimista", sem direcionamento futuro; embora ele admita, quando trata da obra de Fayga, que haja nela qualidades inegáveis.

$\mathrm{Na}$ visão da própria Fayga, não teria havido "realmente nenhum crítico que teorizasse sobre a arte informal" como Pedrosa, entre outros, como feito em nome da arte concreta (Ostrower apud Erber, 2009: 50). Em outras palavras, Fayga entendia que não havia um pensamento teórico sobre 0 Informalismo por parte da crítica brasileira. Entretanto, é possível que ela diferenciasse a constituição de uma teoria daquela de uma crítica, pois, muitos críticos, como Antonio Bento, Lourival Gomes Machado, José Geraldo Vieira, entre outros, comentaram largamente essa produção e, em especial, a da própria Fayga. Em meados da década de 1950, sobre ela escreveram, além do próprio Pedrosa, 
Bento, Machado, Roberto Pontual; nos anos 1970, esse leque se amplia, incluindo: Clarival do Prado Valladares, Jayme Maurício e Walmyr Ayala, entre outros.

\section{0 caso Fayga}

Entre os críticos mais interessados pela produção de Ostrower, sobressaem Maurício e Ayala. 0 primeiro a acompanha entre os anos 1950 e 1970, em textos para exposições e jornais. Na visão de Maurício, também aparece o "paradoxo" entre uma técnica que exige grande controle e uma poética que joga com o acaso, como colocado por Pedrosa.

O ofício do gravador é austero, não permitindo as digressões e surpresas do acaso, tantas vezes reservadas ao pintor. Pressupõe uma presença e uma vigilância muito lúcidas do artista, uma forte ação espiritual a equilibrar a vagareza com que a mão vai vencendo as resistências da matéria rude. (...) A solidez da técnica de Fayga determina o levantamento de estruturas em que não se observam nunca espaços vazios. Nessa trama severa, até os ritmos mais livres se enquadram numa segura ordenação plástica, sem nenhuma intervenção de ordem literária (Maurício, 1956: 14).

O entendimento de Maurício também encontra o de Pedrosa na comparação entre o trabalho de Fayga e a gravura e o desenho orientais, traduzidos em gestos.

A gravura de Fayga (...) não faz concessões, não se compromete com o que não é essencial. Caberia compará-la ainda à poesia do Extremo Oriente - China e Japão - com cujas artes a de Fayga revela grandes afinidades. $O$ sentimento é profundo e preciso em sua obra. Lirismo e tensão muitas vezes definem difíceis equilíbrios (Maurício: 1971).

Nos anos 1970, Ayala salienta a "resistência" de Fayga diante de "qualquer aceno grupal" - a mesma independência que incomodava Pedrosa - e elogia a excepcionalidade da artista: "Fayga nos vem com abstração informal num tempo em que pouco apelo nos chega por este caminho" (Ayala, 1971: 2).

Entendendo que a crítica não teorizava ou debruçava-se suficientemente sobre a arte informal, Fayga tomaria para si essa tarefa, escrevendo artigos para jornais da época. Entre outras declarações, ela diria: "no Brasil, creio que realmente o movimento Informal teve um caráter mais autêntico do ponto de vista da elaboração de algo do nosso contexto. Não seria uma simples imitação porque na época viviase o momento moderno brasileiro" (Ostrower apud Geiger, 2015: 9). Para Geiger, "entende-se que, junto a esse interesse legítimo [por parte de Fayga] em defender a causa do abstracionismo, havia uma compreensão da necessidade de tornar esse saber mais acessível e de forma pedagógica, para transmiti-lo ao público" (Ostrower, 2015: 8). Ou seja, Fayga não apenas dedicava-se a uma pesquisa que conferia à gravura informal um interesse experimental, mas ainda sistematizava os conhecimentos técnico e conceitual para formar artistas nos vários ambientes nos quais atuou como docente, o famoso Ateliê de Gravura do Museu de Arte Moderna do Rio de Janeiro - onde estudaram Geiger e Lygia Pape, entre outros e outras -, além de universidades nacionais e internacionais. Contrariando o conselho de Pedrosa, seu exemplo haveria de ser seguido.

\section{As gravadoras no Museu de Arte Moderna do Rio de Janeiro: fazendo escola}

Sabe-se do largo uso dos livros escritos por Ostrower nos cursos de Artes Visuais em todo país, legando à chamada educação artística uma herança artístico-pedagógica ressonante ${ }^{6}$. Vale retornarmos Geiger 
com o objetivo de exemplificar como o pensamento artístico da gravadora foi levado adiante por suas discípulas.

Em um texto curatorial de Geiger para uma mostra de Fayga, realizada em 2015, a discípula a considera "criadora de um sem-número de obras seminais, essenciais para o contexto do movimento abstracionista informal na arte brasileira, considerado uma das vanguardas dos anos 1950". Segundo Geiger, a formação de Fayga está orientada pelo Expressionismo Alemão, semelhante àquela de Oswaldo Goeldi, artista com quem a artista manteve um proveitoso intercâmbio estético, político, cultural e mesmo de ordem linguística, dado que ambos dominavam o alemão (Geiger apud Ostrower, 2015: 5).

Seguindo essa mesma orientação artística politizada e/ou ideológica, Fayga teria escolhido a gravura, pois

\begin{abstract}
tratava-se de uma postura crítica radical (...) fosse quanto ao alto valor mercadológico da pintura em detrimento da criação gráfica, multiplicável, e, portanto, mais acessível; fosse como protesto social e artístico e também forma de resistência baseada na crença utópica da influência da arte sobre o social - uma convicção da qual compartilhavam, além de Fayga, Goeldi, Livio Abramo e Lasar Segall (Ibidem).
\end{abstract}

No começo dos anos 1950, segundo Geiger, Fayga teria realizado um "gesto dramático, incontrolável..." experimentando a arte abstrata e abandonando a figuração. Em 1957, Ostrower sintetiza a posição da crítica sobre sua obra: "Para eles [os críticos] eu não existia estilisticamente. Isso foi muito mais difícil de eu aceitar do que a acusação de que meu trabalho tinha se tornado decorativo. Eu bem sabia que meu trabalho não tinha nada de decorativo" (Ostrower apud Tavora, 2013: 3).

Aliás, declaração semelhante foi compartilhada por outra gravadora informalista. Edith Behring diria: "eles (os concretistas) seriam os autênticos artistas abstracionistas e nós, meros fazedores de formas decorativas" (Behring apud Tavora, 2012: 11). Entre as obras mais significativas de Behring diante das possibilidades expressivas da gravura abstrata, sem dúvida Gravura III, 1959, da coleção MAC USP, estaria entre as melhores.

No que concerne aos andamentos da gravura contemporânea no país, Maria Luisa Tavora observa 0 experimentalismo da cor na obra de Fayga constituindo um ponto fora da curva no ambiente de uma técnica tradicional como a gravura.

Edith Behring, responsável pelo Ateliê Livre de Gravura do Museu de Arte Moderna do Rio de Janeiro, onde Geiger foi assistente e onde Fayga deu aulas, também foi uma artista referencial para a abstração informalista. Behring compartilhava o mesmo universo de relações profissionais de Fayga, tendo sido aluna de Iberê e Goeldi; e ainda discípula do gravador Johnny Friedlander. Como se sabe, Friedlander capitaneou o Ateliê Livre no seu início, em 1959, passando o comando para Behring em pouco tempo. Com Friedlander, em Paris, estudaram Maria Leontina, Arthur Luiz Piza, Flávio Shiró, Mário Carneiro, Sérvulo Esmeraldo, Henrique Oswald, Rossini Perez, entre outros gravadores e gravadoras brasileiros.

Referindo-se ao período em que lá estiveram, todos sempre mencionam a liberdade com que trabalhavam. Liberdade que era pressuposto das tendências com as quais Friedlaender tivera contato, desde o início de sua formação, como 0 expressionismo alemão, e, em especial, em fase posterior, ligada ao abstracionismo expressivo, campo da chamada arte informal (Tavora, 2012: 62). 
Como explica Tavora, nos dez anos do Ateliê, professores eram substituídos aos poucos por alunos. Tratava-se de um espaço experimental, no qual se acompanhava o debate sobre a ruptura dos suportes, presente no ambiente neoconcreto brasileiro.

\section{Relações expressionistas}

Retornaremos ao assunto do Expressionismo alemão para compreender a trajetória de outras artistas informalistas no contexto nacional. Se Fayga estava evidentemente interessada pelo movimento, bem como Behring, não teriam outros ou outras artistas informalistas provindo de uma genealogia artística semelhante?

Tavora frisa a presença do pensamento de Kandinsky na reflexão de Fayga ${ }^{7}$. Como se sabe, Kandinsky foi uma referência fundamental na formação do olhar e de conceitos por parte de informalistas e expressionistas abstratos em vários cenários geográficos, particularmente na compreensão de que a gestualidade do artista expressaria sua subjetividade ${ }^{8}$. Além disso, é um pioneiro entre os artistas que escreveram teorias sobre a arte abstrata, opondo elementos internos e externos da obra de arte, sendo os primeiros determinados pela "necessidade interior" do artista (Avelar, 2014: 264).

Yolanda Mohalyi, um dos principais nomes até hoje mencionados quando se trata de Informalismo brasileiro, compartilhava desses interesses expressionistas. A pintora também teve alunos e alunas diversos, entre os quais, por exemplo, destaca-se Maria Bonomi, cuja gravura abstrata obteve reconhecimento significativo a partir da segunda metade dos anos 1950. Porém, o percurso de Yolanda é atravessado por outros vieses, como aquele que deriva de sua amizade com Lasar Segall, com quem conviveu intensamente entre 1935 e 1945, ambos originários do leste europeu - ele lituano, ela romena -, tendo estudiosos frisado a proximidade entre a obra de Yolanda desse período em relação àquela de Segall. Alguns comentaristas chegam a ver suas obras como "cópias" segallianas ${ }^{9}$. Tal interpretação nos parece equivocada, dado que inúmeros e inúmeras artistas, ao longo da História da Arte, colaboraram juntos e que isso, ao contrário de ser visto como um problema, é hoje entendido como um lugar profícuo de compartilhamento de ideias ${ }^{10}$. Nessa direção, a história de Eleonore Koch é um exemplo que corrobora nossa compreensão sobre essas relações de troca no ambiente local. Koch teve aulas com Mohalyi, entre outros artistas, antes de conhecer Alfredo Volpi, com quem trabalhou de maneira semelhante àquela empreendida por Mohalyi e Segall. Também Koch foi vista como "discípula" do artista mais velho, mesmo tendo tido experiências anteriores, estudando com outros e outras artistas, como mencionado ${ }^{11}$.

Mais uma vez, chamamos Pedrosa à discussão, desta vez num tom mais brando do que aquele que aparece no artigo sobre Fayga, embora fazendo notar a admiração de Mohalyi por Segall. Ele observa que "Yolanda abre os tons numa palheta menos irisada e mais alta, dentro ainda, porém, da escala de tom a tom, de graves a agudos, do mestre brasileiro". O texto é de 1964 e foi escrito como apresentação para uma individual de Yolanda na galeria Montmartre Jorge, no Rio de Janeiro, estando mais distante no tempo daquele período de defesa aguerrida da arte concreta. No entanto, o crítico não tarda em elogiar o surgimento do que seriam formas mais estruturadas na obra da artista:

um mundo está prestes a definir-se, a sair do informe meramente impressionista: o embrião rítmico, ausente nessa pintura de cozinha bem temperada, anuncia agora como os toques sonoros, longes, interrompidos de uma flauta tímida lá fora, a aproximação de uma presença (...) Só uma boa pintura atinge a comunicação na cordialidade (Pedrosa, 1964). 
Observando o trecho, vemos o julgamento da obra anterior de Mohalyi - "informe meramente impressionista" -, e a afirmação de sua obra atual, para ele, mais estruturada e, por isso, melhor encaminhada. Entretanto, é enigmática a ideia de que a boa pintura comunica quando dispõe de "cordialidade". Vale notar que diversas obras da artista, cobrindo a partir dos anos 1940 aos 1970, estão na coleção do MAC USP e podem estabelecer um diálogo produtivo para se refletir sobre as conclusões do crítico.

\section{Expressionismos, Expressionismos abstratos, experimentações}

A relação entre os conceitos expressionistas e o Informalismo e/ou o Expressionismo Abstrato é evidente na trajetória de muitos e muitas artistas no Brasil e fora dele. Defendiam a presença da subjetividade do artista na obra por meio de sua gestualidade; a necessidade de seu compromisso social com a "expressão" das desigualdades sociais; as especificidades de cada obra dada a singularidade do sentimento de cada artista. Se a mensagem entre os expressionistas era figurativa, na abstração essa mensagem não deixava de existir; apenas ganhava formas estabelecidas individualmente que comunicavam sensivelmente por meio de uma linguagem formal nãorepresentacional.

Fayga, por exemplo, acreditava na intuição como motor da produção artística que não dispensava 0 planejamento racional e acumulava-se pela experiência ${ }^{12}$. Lívio Abramo, ao apresentar uma exposição de Yolanda Mohalyi em Assunção, Paraguai, explica que, embora pareça resultado de um impulso sensível e espontâneo da artista, seu processo estaria longe disso ${ }^{13}$.

Edith Behring, respondendo à pergunta de Geiger e Fernando Cocchiarale sobre a representatividade do Informalismo em relação ao Concretismo nos anos 1950, afirma que a escolha pela arte abstrata geométrica ou não-geométrica era uma questão pessoal, "vinda de dentro":

Eu jamais faria um trabalho concretista devido ao meu temperamento, à minha maneira de pensar. Eu acho que todo mundo deve se exprimir conforme sente, conforme pensa. A estrutura de pensamento é muito variável, felizmente, e por isso as obras de arte também são diferentes" (Behring apud Cocchiarale e Geiger, 1987: 167).

Na mesma entrevista, ela conta que chegou ao ateliê de Friedlander em Paris por indicação de Maria Leontina.

Leontina havia participado da exposição 19 Pintores, em 1947, mostra conhecida por agregar artistas que, naquele momento, desenvolviam pesquisas em torno dos expressionismos, visual e conceitualmente. A artista é conhecida, sobretudo, por sua abstração-geométrica, produzida nos anos 1950, mas reconhecidamente atuou apartada de grupos. Entretanto, no início da década de 1960, Leontina experimentou mais livremente com base numa exploração da grade, na série Formas. Algumas obras se aproximam enormemente da abstração de Antonio Bandeira do mesmo período ${ }^{14}$. Numa análise recente, Paulo Herkenhoff observa que Formas "não se inclui nas variantes do tachismo nem se ajusta bem ao conceito genérico de 'informalismo'. Seria muito redutivo. É facilidade da crítica brasileira classificar tudo informalismo, sobretudo se praticado na França". O comentário do curador nos interessa na medida em que aponta uma idiossincrasia da interpretação crítica local sobre artistas expressivos a qual promoveu - e ainda promove - certa obscuridade acerca de suas produções. Como coloca Herkenhoff, "Formas não é uma pintura do gesto, ação impulsiva sob efeito dos mecanismos de 
'composição' dos elementos do quadro. Leontina viu Rothko" (Herkenhoff, 2010: 184). 0 autor traz ainda para discussão a presença dos expressionistas abstratos na coleção do Museu de Arte Moderna do Rio de Janeiro a partir de 1952, como Baziotes, Stamos e Pollock, que teriam sido referências para a artista. "Essa foi a operação de Leontina: abandonar a geometria pelo informe, por aquilo que, não tendo forma, desclassificava as certezas do cânon construtivo" (Herkenhoff, 2010: 186).

De todo modo, vale salientar a importância de se analisar caso a caso quando o assunto é abstração expressiva, entendendo que artistas independentes se apoiavam apreciando trabalhos realizados e compartilhando, muitas vezes, referências e espaços de trabalho, mesmo que não compondo grupos. Das Formas, Leontina passaria à série Estandartes, com a qual retomaria certa figuração de viés politizado, sendo que o Museu de Arte Contemporânea da Universidade de São Paulo possui a obra Estandarte V, 1963, premiada com aquisição na VII Bienal de São Paulo, exemplo paradigmático dessa série ${ }^{15}$.

Se Leontina marcou presença na historiografia da arte local, Sheila Brannigan, embora presente na maioria das exposições panorâmicas de abstração no país e em coleções públicas e privadas- entre elas, a do MAC USP que conta com as obras O Bizantino, 1960, e Pintura I, 1961 -, é ausente em textos interpretativos de maior fôlego ${ }^{16}$. Pelo que se sabe, Brannigan era inglesa e esteve em São Paulo entre 1957 e 1967 ${ }^{17}$, quando conviveu com o crítico Mario Schenberg e o colecionador Theon Spanudis, participando de diversas edições da Bienal Internacional de São Paulo. Em 1964, Pedrosa escreve sobre a obra da artista para uma exposição na galeria Seta.

Ela ensaia-se a interpretar o mundo e daí aparecer na sua obra algo que não existia ainda - o signo -, isto é, linha ou mancha que se destaca, que se aliena da matéria para valer em si mesmo, como uma nota pessoal, a condensação de uma experiência, uma mensagem (apud Aguilar, 1994: 291).

Embora vista unanimemente como tendo grande conhecimento do ofício, tanto por seus contemporâneos como por curadores de exposições mais atuais, Brannigan não despertou interesse por parte de pesquisadores contemporâneos.

\section{Aprendendo a olhar de novo}

Em 2016, o Denver Art Museum, nos Estados Unidos, realizou uma das primeiras exposições de relevo com artistas expressionistas abstratas norte-americanas num espaço institucional, constituindo um marco na história das exposições dessa tendência. A curadora Gwen Chanzit reuniu obras de artistas das costas leste e oeste, trazendo nomes pouco conhecidos, como Jay DeFeo, Perle Fine, Sonia Gechtoff, Judith Godwin, ao lado das renomadas - embora nem tão reconhecidas assim - Helen Frankenthaler, Grace Hartigan e Joan Mitchell, entre outras. A exposição possuía uma visão canônica do próprio Expressionismo Abstrato - focava na "expressão livre" por meio da gestualidade direta -, mas foi pioneira em seu recorte, trazendo aspectos pessoais da experiência dessas artistas e mostrando como havia muitas mulheres contribuindo efetivamente para essa produção, lado a lado com nomes que foram eleitos pela historiografia e pelo mercado. Chanzit chama atenção para o fato de que até 1986 nenhuma mulher tinha entrado para o rol dos eleitos do famoso História da Arte, de H.W. Janson, um livro referência na formação de grande parte de historiadores e historiadoras da $a^{2} \mathrm{e}^{18}$, incluindo aí o caso brasileiro. 
A pesquisadora e jornalista Mary Gabriel, em 2018, leva adiante o tema, desta vez aprofundando as experiências pessoais de cada uma das artistas, a partir de uma estrutura biográfica, mas apresentando fatos bastante relevantes para a narrativa do Expressionismo Abstrato em sua versão nova-iorquina.

A pesquisa acadêmica norte-americana também tem se dedicado a repensar o Expressionismo Abstrato a partir de suas protagonistas (infelizmente, o mesmo não pode ser dito da cena europeia como um todo). Um caso exemplar é o de Hedda Sterne, a única artista retratada ao lado dos demais "irascíveis" nova-iorquinos na famosa foto de 1950. Sterne expôs em diversas mostras que reuniam expressionistas abstratos, mantinha seu ateliê na 9th Street, onde estavam os demais. Porém, como apontou a crítica Dore Ashton, Sterne não possuía um "estilo" singular - o signature style exigido desses artistas -, ou seja, a artista experimentava em diferentes direções, explorando interesses pautados pela pesquisa da própria pintura e desenho ${ }^{19}$. Nos últimos anos, o trabalho de Hedda tem sido assunto de várias mostras individuais e é nome permanente em recentes mostras panorâmicas de expressionistas abstratos. Entretanto, até pouco tempo, a presença da artista entre os expressionistas abstratos na famosa foto chegou até mesmo a ser interpretada como ocasional, sugerindo que seu lugar ali não havia sido "conquistado".

Outro caso que deve lançar uma luz interpretativa referencial para a questão brasileira é o de Elaine de Kooning, que inicia sua carreira bastante jovem, atuando como pintora e crítica de arte. Nos últimos anos, as produções pictóricas e teóricas de Elaine vêm ganhando estudos que salientam sua atuação singular em termos de autonomia em relação às mulheres artistas da época localizadas no ambiente expressionista abstrato nova-iorquino.

Amy von Lintel e Bonnie Roos exploram o que denominam "escolhas profissionais especificas de gênero" a partir da trajetória da artista, entendendo, por exemplo, que as estadias de Elaine no Texas por longos períodos, entre fins da década de 1950 até sua morte em 1989, em associação com um galerista que representava sobretudo artistas mulheres, nos apresenta outras narrativas sobre 0 Expressionismo Abstrato que se contrapõem a visões mais conservadoras.

Para De Kooning, a pintura de ação do expressionismo abstrato é instanciada não apenas no gesto pictórico, mas igualmente em uma performance ativa de identidade que explora conscientemente as fronteiras fluidas entre 0 mito construído e a vida vivida (Lintel; Roos, 2018: 53)20.

Muitas artistas expressionistas abstratas baseadas em Nova York deslocavam-se anualmente para 0 Texas em busca de público para suas produções, especificamente a partir dos anos 1960. Os valores praticados por Dord Fitz, protagonista dessa empreitada, revelavam o reconhecimento dessas artistas localmente.

Sua série de retratados masculinos com rostos desfigurados foi, repetidas vezes, tida como finalizada por consequência de sua separação do pintor, também expressionista abstrato, Willem de Kooning. Entretanto, a recuperação da produção texana de Elaine comprova o contrário: além desses retratos, a artista também passou a produzir pinturas gestuais mais propriamente abstratas, de uma paleta vibrante e gestualidade evidente. As autoras salientam ainda como o processo de trabalho de Elaine era bastante diferente daquele praticado por seus parceiros homens, pautado em uma teatralidade do corpo cujo exemplo paradigmático são as imagens de Jackson Pollock. Elaine trabalhava pausadamente, porém o resultado eram pinturas repletas da energia da gestualidade. Assim, 
Em contraste, a abordagem de [Elaine] De Kooning à pintura de ação reconceitualizou criticamente as deficiências do movimento que marginalizou vozes, incluindo as de mulheres artistas. 0 mítico oeste americano tornou-se para De Kooning um espaço para explorar sua versão do Expressionismo Abstrato (Lintel; Roos, 2018: 68).

A experiência de Elaine de Kooning no oeste dos EUA endereça diretamente a noção de "pintura de ação", cunhada pelo crítico Harold Rosenberg, um nome imprescindível na conceitualização do Expressionismo Abstrato como tendência tipicamente norte-americana. Como se sabe, para Rosenberg, o gesto vigoroso sobre a tela representava a liberdade da cultura estadunidense, em contraposição à boa forma buscada pela tradição europeia. Na visão de Rosenberg, havia na pintura de ação uma "americanidade" que evocava o mito do self-made man representativo da cultura norteamericana; ao mesmo tempo, ele excluía dessa narrativa indígenas, afrodescendentes e mulheres. Em outras palavras, a importante teoria da pintura de ação não levava em conta as diferenças. Elaine assumiria para sua produção a ideia da pintura como "verbo e não substantivo", rejeitando as "implicações exclusivistas" dessa teoria. As autoras sugerem ainda que, retratando figuras masculinas, a artista subvertia a relação de poder entre o pintor e sua modelo.

Como crítica21 Elaine desafiaria a noção de pureza estabelecida pelo formalismo de especificidade do meio promovido por ninguém menos do que o crítico Clement Greenberg. Segundo Elaine, a visão da arte representacional como ultrapassada era elitista. "A principal diferença, então, entre arte abstrata e não-abstrata é que 0 artista abstrato não precisa escolher um assunto. Mas, quer ele escolha ou não, ele sempre acabará tendo um" (Lintel; Roos, 2018:70). Para ela, a liberdade artística estava justamente em fazer escolhas.

Helen Frankenthaler exemplifica outro aspecto desse cenário. Repetidas vezes uma parcela da crítica de meados do século XX produziu interpretações que destacavam o gênero da artista, descrevendo as cores, formas e efeitos de sua obra como "femininos". Associado a esse adjetivo apareciam outros como "livre", "lírico", "sedutor" e "sensível". A artista respondeu a essas colocações dizendo que não havia bases para se analisar suas pinturas a partir da ideia de terem sido feitas por uma mulher.

A estudiosa Bett Schumacher analisa fotos de Frankenthaler pintando e atenta, em termos de movimento e postura corporal, para a proximidade com a série de fotos de Jackson Pollock, realizada por Hans Namuth. A intérprete explica que Frankenthaler foi vista como uma pintora que levava adiante o "método" pollockiano de pintar, levando-o para gestos suaves, mas que, ao vermos as fotos, percebemos que sua gestualidade era atlética e fisicamente vigorosa. Segundo Schumacher, Frankenthaler buscou superar seu gênero procurando substituir sua presença feminina por uma "presença neutra" (Schumacker, 2010:19). Importante lembrarmos que Greenberg, com quem a artista tivera um envolvimento amoroso, teria mencionado a obra de Frankenthaler apenas uma vez entendendo-a como uma passagem entre a pintura de Pollock e aquela de Morris Louis e Kenneth Nolland - os "abstratos pós-pictoricos", como os denominava o crítico.

\section{Expressivas, abstrato-expressionistas, informalistas: o que há no nome?}

Tendo visto alguns caminhos recentes da produção acadêmica estadunidense no que concerne à reorientação de um olhar sobre o Expressionismo Abstrato levando em conta questões de gênero, pode ser produtivo revermos a obra das artistas estabelecidas no Brasil, já citadas, sob essa luz. 
Elaine de Kooning, como Fayga Ostrower, ocupou-se de fazer arte e escrever sobre a produção de sua época. Elaine, como Fayga, não teve grande reconhecimento pela crítica de seu país. Entretanto, nos Estados Unidos, houve uma crítica escrita por mulheres que se debruçaram sobre a obra de outras mulheres, embora não apenas sobre estas. A título de discussão, recuperemos as análises de Dore Ashton sobre a obra de Hedda Sterne. Ashton percebeu que Sterne explorava vários caminhos simultaneamente e viu nesse experimentalismo sua principal qualidade, embora fosse esse elemento que a colocasse marginalmente em relação a seus contemporâneos expressionistas abstratos. A crítica Barbara Rose incluiu Miriam Shapiro no rol de artistas de seu artigo "llusionismo abstrato", no qual cunhou o termo para discutir o que via como uma recuperação do ilusionismo por parte de artistas abstratos em fins de 1960. A noção de "abstração excêntrica" empregada por Lucy Lippard para descrever uma produção principalmente escultórica que, para ela, reuniria opostos, como o Surrealismo e a estrutura formal, embora incluísse artistas homens, era principalmente dirigida a trabalhos de Eva Hesse, Louise Bourgeois, Lee Bontecou e Yayoi Kusama.

No cenário brasileiro, não encontramos situação semelhante. Praticamente nada se sabe sobre críticas mulheres - como Maria Eugenia Franco - e seu trabalho, entre 1950 e 1960; muito menos se apoiaram mulheres artistas constituindo uma voz interpretativa para elas.

Recentemente, Griselda Pollock escreveu para o catálogo da exposição Modern Women: Women Artists at the Museum of Modern Art. Nele, a autora recupera um protesto organizado por mulheres artistas, críticas, curadoras e historiadoras da arte que marcharam em 1970 em frente ao MoMA reivindicando a presença de mulheres nas exposições. Para Pollock, esse é apenas um entre tantos episódios que demonstram como o Museu, ao longo de sua história, apagou artistas mulheres de suas narrativas modernistas.

Griselda traz então o argumento de que o gênero masculino era associado ao modernismo, em sua versão "alta", enquanto que o feminino era associado à cultura de massa. Ou seja, apagar os traços "femininos" era necessário para que se fosse apropriadamente "moderno". Nesse sentido, as mulheres estavam excluídas das narrativas institucionais, a julgar por aquela construída pelo próprio MoMA.

\begin{abstract}
Longe de ser neutra e indiferente em relação ao gênero, a história da arte museológica tem sido uma inscrição poderosa de uma visão auto-reflexiva, narcisista e masculinista na qual os homens agem e criam e a "mulher" é posicionada como o Outro, um recurso para a arte, uma parte da natureza, reprodução e matéria que a criatividade masculina se esforça para dominar e reformar numa atividade - a criação artística - que faz (o) homem. Esses processos ocorrem em níveis além da consciência individual, intenção ou mesmo compreensão proposital (Pollock, 2010: 39).
\end{abstract}

As exposições individuais de mulheres artistas no MoMA durante os anos 1940, período privilegiado pela autora, eram todas de estadunidenses. Se, por um lado, o Museu se esforçava para incentivar a produção nacional, por outro, sem a presença de artistas mulheres internacionais de maior peso, essas exposições pareciam exceções à regra. Para Griselda, a história narrada pelo MoMA era a história da arte canônica, entendida em sua perspectiva modernista, a partir dos ismos (bastando lembrar dos diagramas de Alfred Barr, nesse sentido). Assim, entendia-se que a arte caminhava da figuração para a abstração e a figura metafórica do artista substituía a representação. Para a autora, a compreensão em termos de arte moderna era a de que "a arte está sempre indo para algum lugar, avançando, desenvolvendo-se e reagindo contra o que foi" (Pollock, 2010: 47). 
Nesse sentido, 0 artista moderno era visto como um herói em termos de agente de mudanças sociais, o que se traduzia, na obra, em transformações formais. Nesse aspecto, a autoria possui um papel significativo uma vez que a obra é entendida como fruto da criação de uma persona artística. "Assim, aos elementos formais aparentemente impessoais de um objeto de arte são anexados a uma biografia explicativa do sujeito da arte: 0 artista" (Pollock, 2010: 47).

Essa interpretação dada por Griselda para o que teria ocorrido com o processo de colecionismo do MoMA possui insights fundamentais para compreendermos, em termos amplos, como: (1) que há intersecções entre o discurso museal e a história da arte em relação à arte moderna e como esse discurso pautou a própria história canônica da arte moderna; (2) o que era definido em termos de um modernismo compreendido pelo MoMA excluía características do "feminino"; (3) a ideia do artista como agente moderno de transformações formais (de linguagem) pressupunha-o como um agente de transformação social; (4) as mudanças formais tinham de ser associadas a uma persona do artista.

\section{Casos à parte}

Seria possível que alguns aspectos dessa caracterização estabelecida pela teórica explicassem, ao menos em parte, o lugar obscuro das expressionistas abstratas e informalistas e de sua produção na narrativa brasileira? E seria possível que houvesse lugar, dentro de um construtivismo masculino dominante local, para artistas mulheres trabalhando no viés expressivo?

Embora tenha havido artistas mulheres envolvidas nos grupos construtivos locais, esse número é ínfimo, se comparado àquele dos homens artistas. Judith Lauand, Lygia Pape e Lygia Clark são os nomes mais mencionados ${ }^{22}$. Já entre expressionistas abstratos ou informalistas, a participação dos homens é que é rara. Além de Antonio Bandeira e lberê Camargo - um caso problemático pois a fortuna crítica não o inclui entre os informalistas -, poderíamos nomear aqueles que ficaram conhecidos como nipo-brasileiros, principalmente associados ao Grupo Seibi em sua segunda organização ocorrida em 1947, como Tikashi Fukushima, Flávio-Shiró e Manabu Mabe. A única mulher nessa conformação era Tomie Ohtake.

Nesse sentido, é produtivo especificar o contorno da inserção da obra de Tomie na historiografia local. Paulo Herkenhoff foi responsável principalmente por ter dado lugar de relevo à série das "pinturas cegas", trabalhos de cunho experimental, antes ausentes da narrativa local. Para ele, a pintura de Tomie foi reduzida pela crítica a um gueto "nipo-brasileiro" que ofuscou a densidade de sua produção e 0 debate que produzia no meio abstrato.

Foi justamente quando o dito projeto construtivo brasileiro enfrentou a crise de 1964 que Tomie Ohtake pareceu esgotar a experiência-limite das pinturas cegas e, paulatinamente, passou a enfrentar, em processo muito particular, o aparente esgotamento das linguagens abstrato-geométricas (Henkenhoff, 2014: 12).

Além de atentar para a sintonia da obra de Tomie com o fim do projeto construtivo local, perceba-se para como o autor remete à "personalidade discreta" da artista, que havia sido mencionada por Pedrosa.

Herkenhoff pontua a proximidade amigável entre Tomie Ohtake e Mário Pedrosa, indicando inclusive que o crítico teria em sua coleção um exemplar das tais "pinturas cegas". Efetivamente, Pedrosa escreve sobre a pintura de Tomie em 1961, descrevendo-a como "uma pintora que ainda está se formando, numa personalidade já desabrochada" (Pedrosa, 1992: 187). Se as "pinturas cegas" são 
produzidas num curto espaço de tempo entre 1959 e 1962, é plausível que Pedrosa tenha pensado nessas telas ao escrever o artigo mencionado. Entretanto, em seu texto, afirma que a obra de Tomie apresenta "quedas" e "pontos altos", vendo nela

uma distância, frequentemente não vencida, entre a personalidade, que se antecipa à obra, e esta, que não consegue amoldar-se ou obedecer aos ditames imponderáveis daquela. Na sua pintura nota-se permanente e patético esforço por alcançar os altos padrões espirituais colocados pela personalidade (Pedrosa, 1992: 188).

Em outras palavras, haveria uma falta de sincronia entre a pintora e sua pintura que poderia ser observada na maneira como se empenha para melhorar seu trabalho artístico. Para ele, apenas em algumas pinturas Tomie teria conseguido alcançar uma "elevação conceptiva, sutileza rítmica, retenção e economia de meios e ímpeto", fazendo a ressalva de que "se a pintora é parca de recursos" isso seria devido ao seu desinteresse pela técnica. Por outro lado, haveria um interesse "pela captação da ideia, isso é, o motivo ou a razão da obra pictórica". O crítico elogia rasgadamente o "calor espiritual" de sua pintura.

Diga-se de passagem, que, em artigo de 1958 sobre Maria Leontina, Pedrosa lançara mão de estratégia semelhante. Embora enaltecesse os trabalhos recentes da pintora e o fato de sua pintura "ser atraída por exigências mais profundas e nobres", afirmou que ela mesma ainda não saberia "definir com precisão quais sejam", indicando assim uma imaturidade da artista em relação à própria obra. No que concernia diretamente ao construtivismo de sua pesquisa, ela usaria como prumo "um cego instinto materno do tato". A indicação de tais análises demonstra que, para ele, essas artistas ainda se esforçavam para alcançarem uma obra "madura", mesmo Leontina já tendo em torno de 40 anos e Tomie cerca de dez anos de carreira, tendo iniciado mais tarde na área.

Se observarmos a escolha do termo "instinto materno" como descritivo da abordagem geométrica empreendida pela artista à luz do que Griselda Pollock intitulada "estereótipo feminino", poderemos compreender melhor como características femininas foram aqui utilizadas para apontar o lugar "cafécom-leite" de artistas como ela no meio cultural local.

Refletimos sobre o significado e a abrangência da equação entre arte feminina e feminilidade, e entre feminilidade e arte ruim, e concluímos que o estereótipo feminino foi uma categoria importante e estruturante no discurso da história da arte. É estabelecido como um termo necessário de diferença, a folha contra a qual um privilégio masculino nunca reconhecido pode ser mantido. A oculta prerrogativa sexual de apropriação masculina da criatividade como atributo inato daquele sexo é assegurada pela afirmação repetida de um negativo, um "outro", o feminino, como ponto necessário de diferenciação e falta (Pollock, 1987: 3).

Para a teórica, a partir do século XIX até meados do XX, tornam-se antagonistas a representação social da mulher (passiva, dependente e realizada apenas na vida doméstica como mãe) e a figura do artista (um criador marginal e original).

\section{A gestualidade e a mancha podem ser femininas}

Como mencionado, a hipótese de Griselda Pollock sobre a coleção do MoMA ser excessivamente masculina é a de que a concepção de modernismo eleita pelo Museu possui contornos simbólicos que remetem ao masculino. Sendo assim, outros modernismos também são possiveis. Ela lembra que a 
"alta modernidade" foi relacionada à "masculinidade" e à "autocontenção", "estruturalmente opondo-se a uma cultura de massa que é representada como intrinsecamente 'feminina". Para Griselda, o feminino viria a se tornar não uma das faces do modernismo, mas o oposto do modernismo que se desejava.

Para ser propriamente moderno, todos os traços de gênero feminino devem ser apagados, permitindo que 0 masculino se apresente como universal e exclusivamente moderno (Pollock, 2010: 37).

Nessa direção, a autora faz uma observação que nos parece essencial. Embora não tenha sido conscientemente planejado, a narrativa do museu incide sobre "sua capacidade de ver o trabalho de artistas mulheres" e compreendê-las a partir de suas experiências específicas. Em outros termos, não se trata de uma construção histórica propriamente arquitetada no sentido de excluir artistas mulheres, mas que assim resulta devido a uma predileção por obras que promovem discursos mais afinados com características predominantemente masculinas. Também nesse sentido poderíamos compreender 0 caso particular das artistas expressivas locais que, a julgar pelas análises de Mário Pedrosa, podem ter sido vistas como tendo optado por formas não-ideais de modernismo - "decorativas" -, no sentido de que as formas orgânicas ou gestualizadas não condiziam com um projeto modernista construtivo de teor desenvolvimentista. Pelo seu contrário, mas da mesma maneira, a ação traduzida num gesto potente, intermediada pelo imaginário expressionista abstrato, era vista como detentora de um sentido masculino, como já indicaram vários intérpretes (Gibson, 1997).

Talvez por isso, o crítico brasileiro não tenha visto os trabalhos de Fayga e Tomie como adequados à perspectiva que nutria a produção artística brasileira. Da mesma maneira, essa inadequação as apartou da narrativa crítica pedrosiana, aliás, uma narrativa que se confunde àquela que se tornou hegemônica em nossa história da arte. Diante disso, podem-se notar indícios do que diferenciaria, por exemplo, "a individualidade solitária" porém "cativante" de Iberê Camargo em oposição à força de Fayga que, caminhando "por si só", tem conduta reprovável. Porém, não parece plausível que a voz de Pedrosa tenha sido o único fator que levou ao apagamento dessas produções abstrato-expressivas elaboradas por artistas mulheres. Lembrando da análise de Griselda, sugerimos que tenha sido uma combinação dessa voz, ecoada por outras, aliadas àquelas institucionais, que compuseram uma narrativa sobre 0 tema. Esta, promovida por escolhas curatoriais, cursos acadêmicos e textos críticos que reiteraram - e ainda o fazem - produziu uma visão unívoca de modernismo local, impeditiva para outras versões que compreendam diretrizes distintas.

Assim, ao longo deste artigo, fizemos uso de abordagens propostas por Griselda Pollock no que diz respeito a uma abordagem que leva em consideração gerações e geografias, pensando a partir das diferenças. Como lembra a autora, obras de arte são produzidas em determinadas realidades e locais singulares por meio de linguagens particulares (Pollock, 2010: 1952). Sendo assim, restaria a nós mapear as especificidades do território a partir do qual o "gesto estético" é elaborado. Assim, perguntamo-nos sobre o que estamos vendo, quem está falando e de onde se está falando.

Sem dúvida Edith Behring, Sheila Brannigan, Fayga Ostrower, Anna Bella Geiger, Maria Leontina, Yolanda Mohalyi e Tomie Ohtake possuíam legitimidade discursiva conferida a elas por sua atuação como artistas, teóricas, professoras. Se suas linguagens, em um momento ou por muito tempo, perpassaram as gestualidades abstrato-expressivas, essa foi uma escolha comprometida com as experiências processuais que buscavam naquele momento e não uma atitude de leviandade diante do debate das abstrações. 
Talvez essas experiências não tenham coincidido com as diretrizes do projeto construtivo, entretanto tiveram ressonâncias no ambiente local, por meio de outros críticos, de suas e seus alunos e, hoje, de curadorias e pesquisas que buscam compreender as direções dessa produção pouco explorada. A própria presença de suas obras na coleção de um museu renomado e associado à Bienal de São Paulo atesta a legitimação de suas produções conferida pelo sistema artístico.

Também levemos em conta como as trajetórias, ideias e poéticas dessas artistas encontraram as de outras artistas de suas gerações num cenário internacional, alargado em termos de experimentalismos gestuais e expressivos.

\section{Referências}

ABRAMO, L. Presentación. In: Yolanda Mohalyi - pintura abstracta. Assunção: Centro de Estudos Brasileiros, 1976.

ALMEIDA, C. Fayga Ostrower, uma vida aberta à sensibilidade e ao intelecto. Hist. Cienc. Saúde-Manguinhos, Rio de Janeiro, v. 13, supl. p. 269-289, out. 2006. Disponível em: <http://www.scielo.br/scielo.php?script=sci_artt ext\&pid=S0104-

59702006000500017\&lng=en\&nrm=iso>. Acesso em: 6 ago. 2020.

Arts District: Women of Abstract Expressionism. Rocky Mountain PBS. Disponível em: $<$ https://www.youtube.com/watch?v=p7tffBOjay 0>. Acesso em: 20 ago. 2020.

AVELAR, A. C. de. Antonio Bandeira, Caos Noturno. Quadro a Quadro. Instituto Moreira Salles. Disponível em: $<$ https://blogdoims.com.br/antonio-bandeiracais-noturno-por-ana-candida-de-avelar/>. Acesso em: 20 ago. 2020.

AYALA, W. A Pura Voz da Gravura. Jornal do Brasil, Rio de Janeiro, Caderno B, p. 2, 17 set. 1971.

AGUILAR, N. (org.). Bienal Brasil Século XX. Nelson Aguilar. São Paulo: Fundação Bienal de São Paulo, 1994.

BRITO, Ronaldo. Lições avançadas do mestre Pedrosa. In: Experiência crítica. São Paulo: Cosac \& Naify, 1999.

COCCHIARALE, F.; GEIGER, A.B. Abstracionismo geométrico e informal. A vanguarda brasileira nos anos cinquënta. Rio de Janeiro: Funarte, 1987.
DE KOONING, Elaine. The Spirit of Abstract Expressionism: Selected Writings. New York: George Braziller, 1994.

ECKHARDT, S. L. Consistent inconsistency: Hedda Sterne's philosophy of flux. Champaign, Illinois, USA: Krannert Art Museum and Kinkead Pavilion, 2006.

ERBER, P. Políticas da abstração: pintura e crítica no Brasil e Japão, anos 1950. Revista Poiésis, Niterói, n. 14, p. 46-59, dez. de 2009.

Breaching the Frame: The Rise of Contemporary Art in Brazil and Japan. Berkeley: University of California Press, 2014.

FARINHA, A. M. A. Coleção Yolanda Mohalyi O Moderno e o Contemporâneo no acervo do MAC USP. 2006. Dissertação (Mestrado em Estética e História da Arte) - Universidade de São Paulo, São Paulo, 2006.

GABRIEL, M. Ninth Street Women. Lee Krasner, Elaine de Kooning, Grace Hartigan, Joan Mitchell, and Helen Frankenthaler: Five Painters and the Movement That Changed Modern Art. New York: Little Brown and Company, 2018.

GIBSON, A. E. Abstract Expressionism: Other Politics, de Ann Eden Gibson. New Haven: Yale University, 1997

GONÇALVES FILHO, A. Exposição reúne Volpi e sua aluna Lore Koch. Jornal O Estado de São Paulo, São Paulo, 20 fev. 2020. Disponível em: $<$ https://cultura.estadao.com.br/noticias/artes,e xposicao-reune-o-mestre-volpi-e-a-aluna-lorekoch,70003203459>. Acesso em: 3 ago. 2020.

HERKENHOFF, P. Maria Leontina. Rio de Janeiro: Papel e Tinta, 2010. 
LINTEL, A. Von ROOS, B. Expanding Abstract Expressionism: Elaine de Kooning, Action Painting, and the American West. American Art, Smithsonian Institution, Summer 2018, 53, vol. 32, n. 2, 2018.

MACHADO, L. G. Fayga Ostrower - gravura. São Paulo: São Luiz, fev. 1962. Arquivo Histórico Wanda Svevo. Fundação Bienal.

MAURíCIO, J. Dois críticos apresentam dois artistas. Correio da Manhã, Rio de Janeiro, Primeiro Caderno, p. 14, 19 ago. 1956.

Fayga Ostrower a partir de hoje na Bonino", Correio da Manhã, Rio de Janeiro, 14 set. 1971.

OSTROWER, F. Fayga Ostrower. Texto e curadoria Anna Bella Geiger. [S.I.]: Insight Comunicação, 2015.

Criatividade e Processos de Criação. Rio de Janeiro: Editora Vozes, 1984.

Universos da Arte. Rio de Janeiro: Editora Campus, 1983.

Acasos e Criação Artística. Rio de Janeiro: Editora Campus, 1990.

A Sensibilidade do Intelecto. Rio de Janeiro: Editora Campus, 1998.

NELSON, A. Sobre el género y la superficie en la abstracción temprana de Lygia Clark. In: Lygia Clark. La pintura como campo experimental, 1948-1958. Bilbao: Museo Guggenheim, 2020.

OHTAKE, T. Pinturas cegas. Texto e curadoria Paulo Herkenhoff. Porto Alegre: Fundação Iberê Camargo, 2012.

_. Tomie Ohtake: gesto e razão geométrica. Texto e curadoria Paulo Herkenhoff. São Paulo: Instituto Tomie Ohtake, 2014.
PEDROSA, M. Dos muros de Portinari aos espaços de Brasilia. Org. Aracy Amaral. São Paulo: Perspectiva, 1992.

Yolanda Mohalyi. In: Yolanda Mohalyi Rio de Janeiro: Galeria Montmartre Jorge, 1964.

POLLOCK, G. The missing future: MoMA and modern women. In: Modern Women: Women Artists at the Museum of Modern Art. New York: Alexandra Schwartz, 2010.

RUBINO, I. M. Entrevista Anna Bella Geiger 2014/2015 acerca de sua fase visceral (19651969). DAPesquisa, Florianópolis, v. 11, n. 17, p. 101-112, dez. 2016.

SALVATORI, M. A gestualidade em lberê Camargo: obra gráfica de 58 a 69. Revista Estúdio, Lisboa, vol. 3, n.5, p.13-17, verão 2012.

SCHUMACHER, B. The Woman Problem: Gender Displacement in the Art of Helen Frankenthaler. Woman's Art Journal, vol. 31, n. 2, Fall/Winter 2010. Disponivel em: <http://www.jstor.org/stable/41331080>. Acesso em: 20 ago. 2020.

TAVORA, M. L. Luz. O Ateliê livre de gravura do MAM-Rio - 1959/1969 projeto pedagógico de atualização da linguagem. Disponível em: $<$ https://www.ppgav.eba.ufrj.br/wpcontent/uploads/2012/01/ae15_maria_luisa_tav ora.pdf>. Acesso em: 20 ago. 2020.

. Fayga Ostrower e a Gravura Abstrata no
Brasil. In: SEMINÁRIO VANGUARDA E
MODERNIDADE NAS ARTES BRASILEIRAS,
2005. São Paulo. Anais eletrônicos..., p. 4.
Disponível
em:<http://www.iar.unicamp.br/dap/vanguarda/
artigos_pdf/maria_luiza.pdf>. Acesso em: 30
set. 2020.

TRIZOLI, T. Atravessamentos feministas: um panorama de mulheres artistas no Brasil dos anos 60/70. Tese (Doutorado em Educação). Faculdade de Educação da Universidade de São Paulo. São Paulo, 2018.

\section{Notas}

\footnotetext{
* Professora adjunta do curso de Teoria, Crítica e História da Arte, do Departamento de Artes Visuais da Universidade de Brasília (VISUnB) e curadora da Casa Niemeyer (UnB).E-mail: <anacandidaavelar@gmail.com>.ORCID: <https://orcid.org/0000-0002-7026-7160>. 1 "Ela começou como gravadora numa época em que predominavam os vários modos de abstracionismo, sobretudo o que se chamou de abstracionismo lírico. 0 tachismo a seduziu e ela se entregou, aliás legítima, à busca de feitos de mancha, de textura que a chapa em metal, os ácidos e os pós e os acasos tão generosamente produzem, provocam ou insinuam. Tais exercícios, quando se fica neles, embotam. Mas quando se integram no fazer e na experiência do gravador-artista, enriquecem-no" (Pedrosa, 1992: 110). Publicado originalmente como: "Anna Bella Geiger," Correio da manhã, Rio de Janeiro, 6 fev. 1968.
} 
2 Uma das gravuras informalistas mais divulgadas de Anna Bella Geiger - A um Azul Profundo, llimitado..., 1965 -- está na coleção do Museu de Arte Contemporânea da Universidade de São Paulo. Todas as obras aqui mencionadas pertencentes a esse acervo podem ser visualizadas no site do Museu de Arte Contemporânea da Universidade de São Paulo no endereço $<$ https://acervo.mac.usp.br/acervo/index.php>.

${ }^{3}$ Para se compreender melhor a visualidade produzida por Fayga nesse período, vale conferir o acervo do MAC / USP, que possui 22 obras da artista. Em particular, há obras da segunda metade da década de 1950, incluindo uma de 1957, sem título, que iluminam as falas do crítico.

4 "Para qualquer pessoa ligada ao meio de arte brasileiro, especialmente para alguém que esteja investido de uma função crítica nessa área, parece impossível falar sobre Mário Pedrosa sem alguma dose de passionalismo. [...] ele impregnou o circuito com suas ideias e suas posiçõees diante do trabalho de arte" (Brito, 1999: 48).

${ }^{5} \mathrm{O}$ pesquisador e professor brasileiro Pedro Erber, atuante no exterior, discutiu o tema em várias oportunidades (Erber, 2014).

Sobre o Gutai, Pedrosa foi categórico: "São tachistas e procuram antes o pretenso informe das origens do que a definição de estruturas novas" (Pedrosa apud Erber, 2009: 47).

${ }^{6}$ Nomeadamente Criatividade e Processos de Criação, de 1977; Acasos e Criação Artística, 1990, além de A Sensibilidade do Intelecto, de 1998 - datas das primeiras edições -, pelo qual a gravadora recebeu o Prêmio Literário Jabuti, em 1999. Na Universidade de Brasília, constam disciplinas que utilizam as publicações de autoria de Fayga Ostrower nos Departamentos de Artes Visuais (pósgraduação), Design e Comunicação (Graduação). Na Universidade Federal do Rio de Janeiro, ela aparece em disciplinas da Escola de Educação Física e Desportos (pós-graduação em Dança); e na Escola de Artes, Ciências e Humanidades da Universidade de São Paulo - campus Leste (Graduação), apenas para um breve panorama dessa presença.

7 "A nosso ver, ela atualiza o caminho esbocado por Kandinsky, para quem a verdadeira arte nasce de uma necessidade interior" e se comunica a nós pela totalidade dos sentidos. Num processo muito peculiar de trabalho, a artista chama um a um os elementos formais para participarem do mundo de emoção que ela cria para o espectador" (Tavora, 2005: 23).

${ }^{8}$ Em Nova York, o Museu de Arte Não-Objetiva, fundado em 1939 a partir da coleção de Solomon Guggenheim, com vários trabalhos de Kandinsky, teve papel fundamental nesse aspecto formativo para os jovens expressionistas abstratos durante a década de 1940.

9 "Muitos autores afirmam que Segall exerce uma forte influência sobre a artista, criando mesmo uma relação de dependência da qual Yolanda custa a se libertar. Prova disso, seria a transformação de uma das características centrais da trajetória da artista: a prática de uma pintura figurativa, voltada para o pós-impressionismo para uma poética de estilo expressionista - como uma "cópia carbonada" de Segall. Para esses autores, somente a partir da década de 1950 é que Yolanda ganha autonomia plena ao iniciar a fase abstrata, na qual permanece até o fim da vida" (Farinha, 2006: s.p.).

10 Ver exemplos famosos como Gabriele Münter e Wassily Kandinsky, Barbara Hepworth e Ben Nicholson ou Elaine e Willem de Kooning. Embora fossem tidos como "casais", a relação entre eles e elas era de parceria intelectual e artística (Gabriel, 2018).

${ }^{11}$ Mesmo recentemente, por ocasião de uma mostra com obras de Koch e Volpi, a noção de discípula é reforçada (Gonçalves Filho, 2020).

12 "Fayga Ostrower". Disponível em: <https://www.youtube.com/watch?v=M4p0ORnWI2E >. Acesso em: $1^{\circ}$ ago. 2020.

13 "el agudo sentido del color y de la forma que posee la artista, su exquisita sensibilidad consiguen expresar, con rara fuerza, lo que parece obedecer solamente a un impulso incontrolado y vago" (Abramo, 1976: s.p.).

14 Para saber mais (Avelar, s.d.).

15 Judith Lauand também teve suas experiências abstrato-líricas, nas quais a grade permanecia como elemento estruturante. Infelizmente, ainda não há estudos sobre esse aspecto de sua obra, dificultando a análise do assunto. Ver, por exemplo, Sem Título, 1968, betume e pigmentos sobre madeira (Judith Lauand: experiências. São Paulo: Museu de Arte Moderna, 2011. Curadoria e texto Celso Fioravante).

${ }^{16}$ Entre as coleções brasileiras, há obras de Brannigan no Museu de Arte Contemporânea da USP, no Museu de Arte do Rio e no Museu de Arte Moderna de São Paulo. Uma busca online mostra diversos leilões comercializando trabalhos da artista.

17 Tentamos contato com a família de Brannigan, mas sem sucesso. Sua filha é a fotógrafa Maureen Bisilliat.

18 Arts District: Women of Abstract Expressionism. Rocky Mountain PBS. Disponivel em: <https://www.youtube.com/watch?v=p7tlfBOjay0>. Acesso em: 20 ago. 2020.

${ }^{19}$ No catálogo da exposição Consistent inconsistency: Hedda Sterne's philosophy of flux, realizada em 2006, a curadora Sarah L. Eckhardt esclarece: "The opposite of art critic Clement Greenberg in outlook, Sterne engaged such a range of influences not for their roles in art historical progression, but as simultaneous and infinite aesthetic possibilities" (Eckhardt, 2006: 11). Ela também traz dados sobre o número de mostras das quais Sterne participou entre 1950 e 1960, lembrando que sua obra figura nas principais coleções norte-americanas como MoMA, MET, Whitney, Art Institute of Chicago, entre outras.

${ }^{20}$ Artigos em inglês aqui citados foram por mim traduzidos para fins de pesquisa.

${ }^{21}$ Consultar, por exemplo: (De Kooning, 1994).

22 Embora Mário Pedrosa tenha defendido tanto a obra como a própria Lygia Clark em diversas oportunidades, em 1952, no início da carreira, a artista recebeu críticas duras ter apenas o bom gosto como qualidade feminina. Como observou a historiadora da arte Adele Nelson, ele recriminava "refinamento excessivo" da artista. (Nelson, 2020).

Artigo recebido em setembro de 2020. Aprovado em dezembro de 2020. 